\title{
Cyclophosphamide/Methotrexate Regimen
}

National Cancer Institute

\section{Source}

National Cancer Institute. Cyclophosphamide/Methotrexate Regimen. NCI Thesaurus.

Code C10801.

A regimen consisting of oral cyclophosphamide and methotrexate that may be used in the treatment of metastatic breast cancer. 